\title{
Paste and thickened tailings water benefits - case studies
}

Jerold Johnson WesTech Engineering, Inc, USA

Wei Xie WesTech Engineering, Inc, USA

\begin{abstract}
In today's world, mining is faced with many evolving requirements and challenges that come to a head in the handling of the plant tailings. Many of which are directly related to the use and conservation of water. Water availability is reducing as the world's demand for it expands. This is particularly true in arid climates like that of Inner Mongolia China. Water supply for the Baotou Steel mine and the livelihood of the nearby communities is supported by a $130 \mathrm{~km}$ long pipeline (the longest in China) which draws from the Yellow River. Conservation of this precious resource was one of the main drivers for the use of P\&TT technology management of the plant tailings. The water recovery at the iron mine is successfully and consistently achieving above 95\%. Recovery of the water at the paste thickeners eliminates or greatly reduces the existence of any free standing water in the tailings deposition unlike within slurry ponds where free water pools on the surface and large volumes are lost to evaporation and allows fluidization during slurry pond dam failures. This paper presents some case studies of China P\&TT installations in arid and wet climates.
\end{abstract}

\section{Introduction}

Paste and Thickened Tailings, (P\&TT) technology has provided many benefits for tailings management. Using thickeners to produce this non-Newtonian suspension can be an economic method to recover water at the plant and reduce water loss at the tailings impoundment. Water management can be critical for the operation of the plant. Of particular note is the benefit of having little or no free water on the P\&TT impoundment, reduces the potential of failures and the damage resulting from it (Polley, 2015). Traditionally, the majority of the water loss for a plant is associated with the tailings. Water recycled from the some slurry ponds are estimated to 20 to $25 \%$ of the water sent to conventional ponds (Barnes and Gates, 1984). Three general water consumers for traditional deposited tailings are evaporation, seepage, and water trapped with the solids, particularly the loosely compacted fines. The climate will dictate the significance of the evaporation portion of the water loss and liners can address seepage. The trapped water is a function of particle size distribution. P\&TT technology reduces the water loss for all three of these consumers (Brackebusch and Shillabeer, 1998; Robinsky, 1999).

This water balance significance of P\&TT has been documented in the Khumani Iron Mine in South Africa. This Greenfield plant was permitted to be installed due to the water benefits of P\&TT (du Toit and Crozier, 2012). The permitting of this site hinged on the mine demonstrating that the water consumption would be less than $0.09 \mathrm{~m}^{3} / \mathrm{t}$ of product. The P\&TT system used a two stage thickening with a high rate thickener located at the plant (90 m units), the underflow from which is pumped $5 \mathrm{~km}$ to the paste thickener (18 $\mathrm{m}$ units) at the disposal site $5 \mathrm{~km}$ away. The paste overflow (approximately $70 \%$ of the stage one underflow water) is then returned to the plant and the P\&TT underflow is surface stacked in a shallow valley site. The water recovery at this site is as high as $98 \%$. 
This paper focuses on two P\&TT sites in China, the Baotou iron plant in Inner Mongolia and the ZiJin Gold/Copper Mine in Southeastern China. These two sites show the P\&TT benefits in extreme climates from arid to subtropical.

\section{Case study \#1 - Boatou Steel, Inner Mongolia}

The climate at Baotou is arid and the water for the site and the surrounding community is pumped $130 \mathrm{~km}$ pipeline from the Yellow river. This pipeline transports $2,500 \mathrm{~m}^{3} / \mathrm{h}$ of water. Conservation of this valuable resource is one of the reasons that P\&TT was considered for this site (Ausenco, 2010).

P\&TT system was investigated for this Greenfield site by conducting a pilot plant study in 2008 . The pilot test was conducted at a different operating iron plant about $200 \mathrm{~km}$ from the new plant. The high density type underflow was produced in a 1-m WesTech pilot plant and the underflow angle of repose was studied in 1 by $10 \mathrm{~m}$ troughs constructed of sheet metal. The pilot plant results showed that an underflow of about 73 wt $\%$ solids could be produced as a high density underflow that produced a 2 3\% angle of repose.

Care must be taken when designing new plant based on data from a completely different plant. Parameters such as particle size distribution, PSD, mineralogy, and water chemistry have profound effects on the yield stress versus solids wt\% relationship. The Baotou plant produced the designed yield stress and the stacks with an acceptable angle of repose, but the associated wt\% solids was $70 \sim 71 \mathrm{wt} \%$.

The Baotou site uses a high rate thickener located at the plant. The thickener underflow is pumped $2.6 \mathrm{~km}$ to the $20 \mathrm{~m}$ diameter WesTech paste thickeners located near the deposition site. The P\&TT tailings are then pumped $0.5 \sim 2.9 \mathrm{~km}$ to a set of spigot discharge points along the containment dykes. The impoundment is in a shallow valley with the boundary structure on the downhill sides. The spigots are along this boundary dyke, see Figure 1.

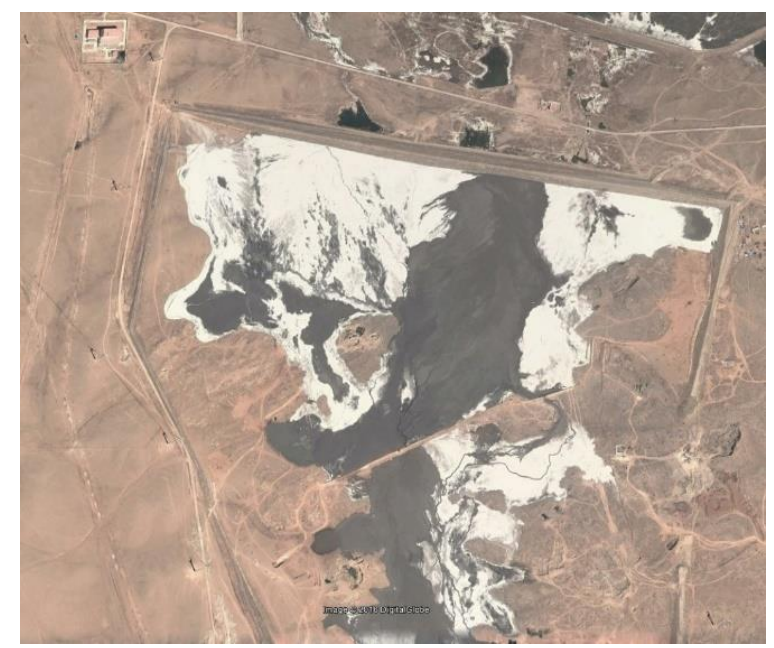

Figure 1 Baotou Steel surface stack layout showing the $2 \mathrm{~km}$ down valley dyke

The water balance of this site is provided in Table 1 . The iron recovery process sends a tailings stream to the first thickener with about $8,000 \mathrm{~m}^{3} / \mathrm{h}$ water (about 9 wt\% solids). The high rate thickener produces $45 \sim 50$ wt\% solids and recovers about $90 \%$ of this water. The paste thickener stage recovers an additional $59 \%$ for a total recovery of $95 \%$. The paste thickener overflow of $518 \mathrm{~m}^{3} / \mathrm{h}$ is about a $2 \%$ savings of the water pipeline flow. The water recovered at the thickener has excellent clarity with $<50 \mathrm{ppm}$ and is recycled to the process. 
Water balance around the two stage thickening circuit at Baotou Steel

\begin{tabular}{ccccc}
\hline Stage & $\begin{array}{c}\text { Water in feed } \\
\left(\mathbf{m}^{3} / \mathbf{h}\right)\end{array}$ & $\begin{array}{c}\text { Water in overflow } \\
\left(\mathbf{m}^{3} / \mathbf{h}\right)\end{array}$ & $\begin{array}{c}\text { Water in underflow } \\
\left(\mathbf{m}^{\mathbf{3}} / \mathbf{h}\right)\end{array}$ & Stage recovery \\
\hline WesTech High rate thickener & 8335 & 7460 & 875 & $89.5 \%$ \\
WesTech Paste thickener & 875 & 518 & 357 & $59.1 \%$ \\
\hline
\end{tabular}

\section{$3 \quad$ Thickener control}

One important factor for water recovery at a paste thickener is proper thickener control. Though thickener operation is not difficult, consistent operation is very beneficial. The Baotou paste thickener is operated manually with the operator responding to control room data to select operating conditions. It is recommended that two control loops be used for the control of the thickener. First, consistent flocculant dosage should be maintained. Second, the solids residence time needs to be steady, by controlling the bed level or solids inventory in the thickener. Proper control of these two process steps will improve the water recovery and the thickener operation.

Proper flocculation is critical in optimizing the underflow wt\% solids in a paste thickener. This relationship was shown at the Lisheen lead/zinc plant in Ireland as presented in Paste 2006 (Shaw and MacNamara, 2006). Their systematic study showed that the average underflow density increased as the flocculant dosage was reduced. The optimum was found to be at the dosage predicted by bench-scale studies. A similar trend can be seen in the Baotou operating data for 8 days of operation, Figure 2. During this period the flocculant dosage varied between 20 and $35 \mathrm{~g} / \mathrm{t}$. The mine practice was for the operator to select the flocculant flow rate in anticipation of the solids throughput. This allowed the dosage to vary as the solids throughput varied. The data is grouped together for each day. The general overall trend shows a benefit to increase the underflow wt\%. The variation during each day can be seen; a result of normal operating feed changes and other thickener operation variations (like bed level) that affect the underflow wt\%.

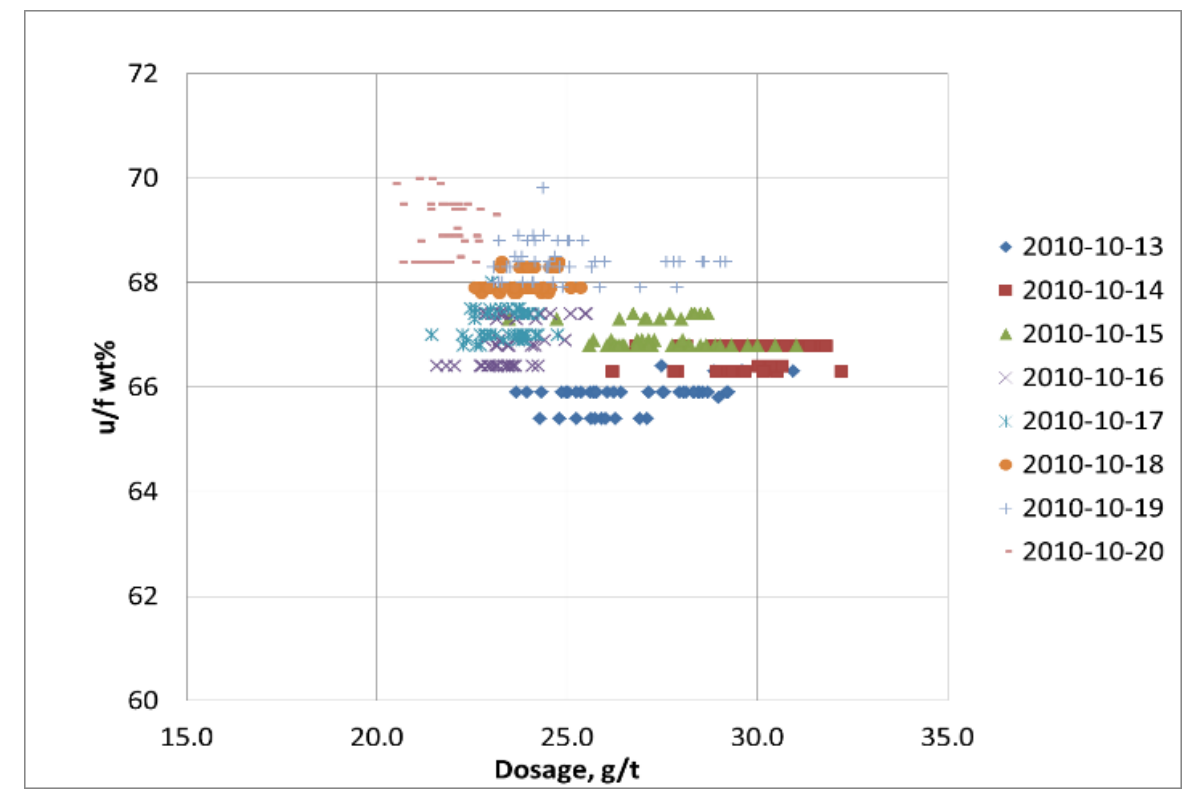

Figure 2 Baotou underflow (wt\%) versus dosage $(\mathrm{g} / \mathrm{t}$ )

The other important control is to maintain the bed level with in the thickener. The ability to produce the nonNewtonian underflow is dependent on the residence time of the solids in the thickener. The higher the yield stress the longer the time needed. For the operation of a thickener, this principle relates to be volume. For a given solids feed rate, the greater the volume of solids, the longer the residence time. The amount of solids in the thickener can be tracked with a pressure gauge on the bottom of the tank. This gives a reading of the 
inventory or total weight above the gauge. Based on a few assumption and experience the target bed pressure can be calculated. The effect of operating at higher bed pressures is seen in Figure 3 . As the pressure is increased from 373 to $379 \mathrm{kPa}$ the underflow wt\% increased from 69 to $70 \mathrm{wt} \%$. The thickener was operated at lower residence time and then a new target bed pressure was selected. The quick change ( 6 total hours, the data was collected every 0.5 hour) between the shorter bed residence time and the longer time is shown. The grouping at the lower pressure and upper pressures shows the ability of manual operation to control the thickener. There are many parameters affect the underflow density in addition to residence time which provides some degree of variability of the data.

The combination of flocculant optimization and bed pressure optimization will produce the maximum underflow wt\% and the maximum water recovery.

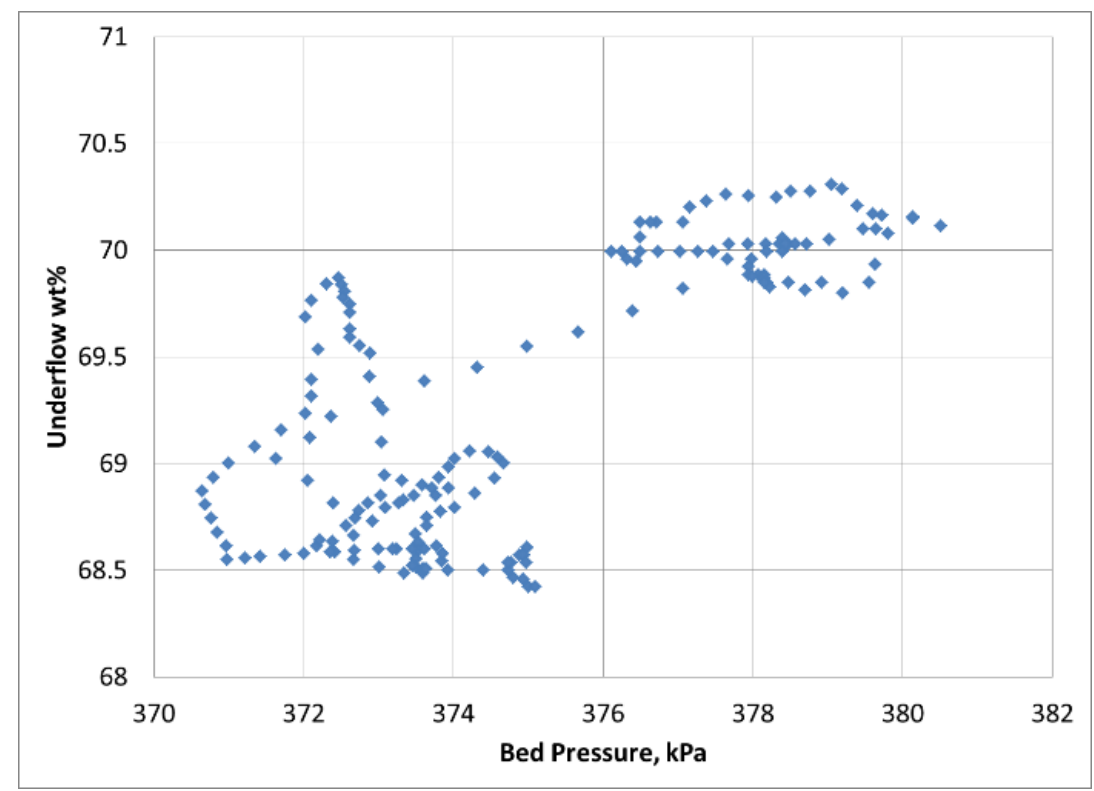

Figure 3 Baotou underflow (wt\%) versus bed pressure

\section{$4 \quad$ Case Study \#2 - ZiJin Gold/Copper Mine, Southeast China}

This site is located in a monsoon-influenced humid subtropical climate with heavy rainfall. With four months averaging $200 \sim 300 \mathrm{~mm}$ of precipitation, water management is critical. This site uses three WesTech paste thickeners; two on separate tailings streams and one thickens the precipitate from a water treatment stream. This paper will focus on the water treatment stream system.

Processing the gold and copper at this site requires multiple water streams. The WesTech $15 \mathrm{~m}$ diameter paste thickener thickens the precipitate from a water treatment plant using $\mathrm{Na}_{2} \mathrm{~S}$ and $\mathrm{CaO}$ to remove dissolved salts. The stream has a fine grain size precipitate that is thickened to a low yield stress underflow and placed in a pond in a steep valley see Figure 4 . The site is surrounded on three sides by steep mountain slopes and is up valley of one of the plant's heap leach operation (lower right in photo) and water holding ponds. 


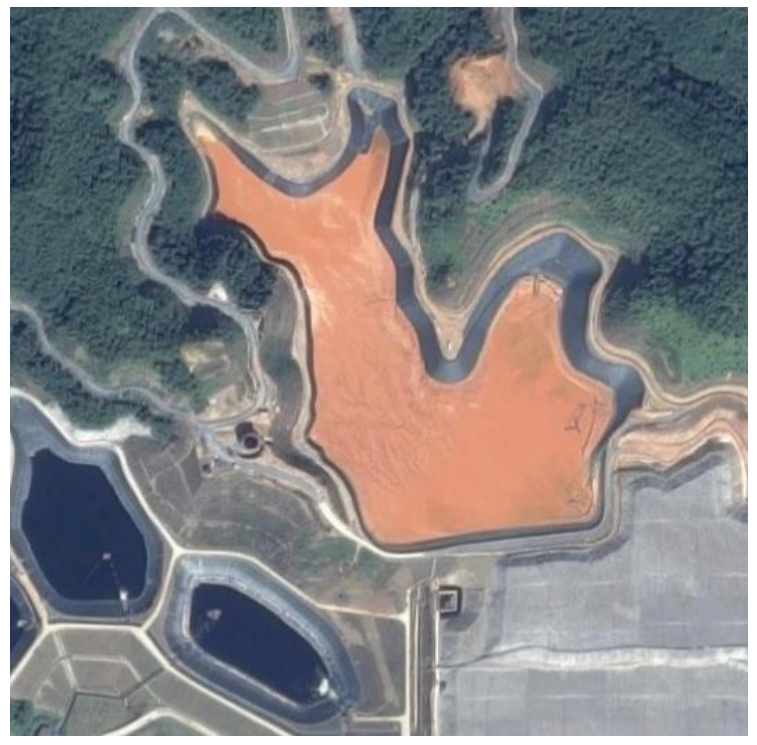

\section{Figure 4 ZiJin P\&TT site}

The site water management includes diverting the large volumes of rain water from the surrounding mountains around the pond, see Figure 5 . The site drainage channel can be seen as the white structure in the center of the photo. The P\&TT is slowly covering the channel. The paste thickener is located at the site and centrifugal pumps transport the P\&TT to spigots around the pond boundary. The pond has little or no free water with the use of P\&TT and the diversion of the drainage around the site.

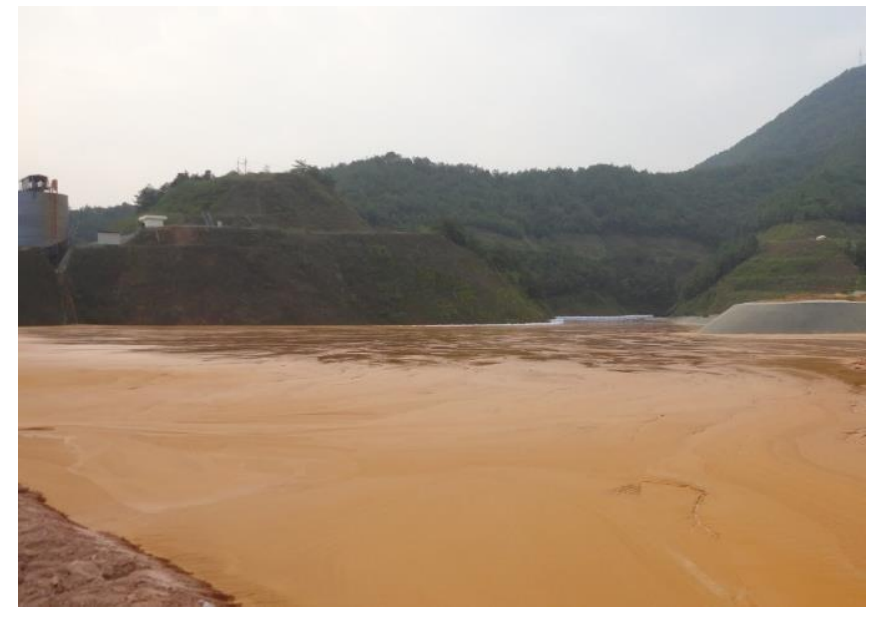

\section{Figure 5 ZiJin thickener location and drainage view}

The increase in water recovery for this stream is shown in Table 2. The feed to the paste thickener is a combination of a high rate thickener underflow and additional process flow that results in about $8 \mathrm{wt} \%$ solids and $368 \mathrm{~m}^{3} / \mathrm{h}$ water. This feed comes from the treatment plant $>2 \mathrm{~km}$ across the valley. The paste thickener produces a 30 31 wt\% solids underflow and recovers an additional $297 \mathrm{~m}^{3} / \mathrm{h}$ resulting in an overall $93 \%$ water recovery. The water recovered at the thickener has excellent clarity with less than $30 \mathrm{ppm}$ and is reused in the process. 
Table 2 Water balance around the two stage thickening circuit at ZiJin Gold

\begin{tabular}{ccccc}
\hline Stage & $\begin{array}{c}\text { Water in feed } \\
\left(\mathrm{m}^{3} / \mathrm{h}\right)\end{array}$ & $\begin{array}{c}\text { Water in } \\
\text { overflow } \\
\left(\mathrm{m}^{3} / \mathrm{h}\right)\end{array}$ & $\begin{array}{c}\text { Water in } \\
\text { underflow } \\
\left(\mathrm{m}^{3} / \mathrm{h}\right)\end{array}$ & $\begin{array}{c}\text { Stage } \\
\text { recovery }\end{array}$ \\
\hline $\begin{array}{c}\text { Combination of a high rate thickener and } \\
\text { other streams }\end{array}$ & $\begin{array}{c}1035 \\
\text { (estimated) }\end{array}$ & 667 & 368 & $64.4 \%$ \\
WesTech paste thickener & 368 & 297 & 71 & $80.6 \%$ \\
\hline
\end{tabular}

\section{Conclusion}

An important benefit of P\&TT technology is improved water recovery. Water loss from the tailings stream can be contributed to evaporation, seepage, and water trapped with the solids. The use of P\&TT technology and methods can reduce the water loss to each of these three categories. The water is recovered at the thickener producing a non-Newtonian suspension underflow that achieves a higher final density of the tailings, the overall recovery is increased. This paper provides two case studies demonstrating this. One site is in an arid climate and the other is located in a subtropical climate.

\section{References}

Ausenco PSI 2010, 'Bao Tou Iron Concentrate, Water, Thickened Tailings System', www.ausenco.com/case studies/bao-tou-bai-yun Barnes, E.B. and Gates, P.D. 1984, 'Final environmental impact statement red dog mine project', BiblioGov. Brackebusch, F. and Shillabeer, J. 1998, 'Use of paste for tailings disposal', Minefill, pp. 53-58.

du Toit, T. and Crozier, M. 2012, 'Khumani iron ore mine paste disposal and water recovery system', the Journal of the Southern African Institute of Mining and Metallurgy, vol. 112, no. 3, pp. 211-220.

Polley 2015, 'Report on Mount Polley Tailings Storage Facility Breach', in Independent Expert Engineering Investigation and Review Panel. Under the directive of the Province of British Columbia, pp. 95.

Robinsky, E.I. 1999, 'Thickened tailings disposal in the mining industry (Chap 2)'. Quebecor Printpak.

Shaw, A. and MacNamara, L. 2006, 'Design and Commissioning of the Lisheen Backfill Plant', in R.J. Jewell, S. Lawson and P. Newman (eds), Proceedings of the Ninth International Seminar on Paste and Thickened Tailings, Australian Centre for Geomechanics, Perth, pp, 347-358 